\title{
Memory Plasticity Across the Life Span: Uncovering Children's Latent Potential
}

\author{
Yvonne Brehmer \\ Max Planck Institute for Human Development and Saarland \\ University
}

\author{
Shu-Chen Li \\ Max Planck Institute for Human Development
}

Viktor Müller, Timo von Oertzen, and Ulman Lindenberger
Max Planck Institute for Human Development and Saarland University

\begin{abstract}
Memory plasticity, or the ability to improve one's memory performance through instruction and training, is known to decline during adulthood. However, direct comparisons among middle childhood, adulthood, and old age are lacking. The authors examined memory plasticity in an age-comparative multisession training study. One hundred and eight participants ages 9-10, 11-12, 20-25, and 65-78 years learned and practiced an imagery-based mnemonic technique to encode and retrieve words by location cues. Individuals of all ages were able to acquire and optimize use of the technique. Older adults and children showed similar baseline performance and improvement through mnemonic instruction. However, in line with tenets from life-span psychology (P. B. Baltes, 1987), children profited more from mnemonic practice and reached higher levels of final performance than did older adults.
\end{abstract}

Keywords: aging, child development, episodic memory, lifespan, plasticity and training

Life-span psychology conceptualizes development as individuals' lifelong adaptation to and mastering of constraints and opportunities imposed and provided by developmental contexts (Baltes, Lindenberger, \& Staudinger, 2006; Li, 2003; see also Craik \& Bialystok, 2006). Adaptation, or the interplay between assimilating the environment to existing forms of thought and action and accommodating these thoughts and actions to environmental features (e.g., Piaget, 1952), requires flexibility (or plasticity) on the part of developing individuals. Such flexibility entails the modi-

Yvonne Brehmer, Viktor Müller, and Ulman Lindenberger, Center for Lifespan Psychology, Max Planck Institute for Human Development, Berlin, Germany, and School of Psychology, Saarland University, Saarbrücken, Germany; Shu-Chen Li, Center for Lifespan Psychology, Max Planck Institute for Human Development; Timo von Oertzen, Center for Lifespan Psychology, Max Planck Institute for Human Development, and Department of Mathematics, Saarland University.

This study was carried out in the context of the research group Binding: Functional Architecture, Neuronal Correlates, and Ontogeny, funded by German Research Foundation Grant DFG FOR 448, and conducted in partial fulfillment of the requirements for the doctoral dissertation of Yvonne Brehmer. The dissertation work was also supported by a stipend from the Life Course: Evolutionary and Ontogenetic Dynamics (LIFE) program of the International Max Planck Research School.

We thank Paul B. Baltes, Lars Bäckman, Christopher Hertzog, Martin Lövdén, Tim Salthouse, Yee Lee Shing, and Hubert Zimmer for helpful comments on earlier versions of this article. We also thank Michael Schellenbach for technical assistance.

Correspondence concerning this article should be addressed to Yvonne Brehmer, who is now at the Aging Research Center, Gävlegatan 16, S-11330, Stockholm, Sweden, or to Shu-Chen Li, or Ulman Lindenberger, Center for Lifespan Psychology, Max Planck Institute for Human Development, Lentzeallee 94, 14195, Berlin, Germany. E-mail: yvonne.brehmer@ki.se, shuchen@mpib-berlin.mpg.de, or lindenberger@mpib-berlin.mpg.de. fiability of the ranges of possible developmental processes, events, and outcomes (Baltes et al., 2006; see also the notion of the zone of proximal development, i.e., Vygotsky, 1978). In the cognitive domain, life-span developmental psychologists seek to describe and explain age differences in the ranges and limits of cognitive plasticity in addition to age differences in initial levels of functioning. Whereas the level of information characterizes performance that the individual is currently capable of under existing contextual conditions, cognitive plasticity reflects an individual's latent potential under altered conditions. As such, it points to driving forces of individual and developmental differences in future cognitive status.

Baltes (1987; cf. Kliegl \& Baltes, 1987; Lindenberger \& Baltes, 1995) distinguished between three levels of performance that together provide a comprehensive account of an individual's plasticity profile. Baseline performance indicates the individual's initial status (level) of performance on a given cognitive task without additional intervention or support. Baseline reserve capacity, or baseline plasticity, refers to the extended range of possible performance when interventions in the form of additional resources (e.g., cognitive strategies or additional cues) are provided. Developmental reserve capacity, or developmental plasticity, refers to a further extension of performance after task conditions have been altered with the aim to fully activate, and possibly expand, an individual's task-relevant cognitive resource (e.g., through extensive practice that optimizes strategy or cue utilization).

Adult cognitive training research over past decades has accumulated evidence on the course of cognitive plasticity in adulthood and old age, particularly with respect to episodic memory and fluid intelligence (cf. Baltes \& Lindenberger, 1988; Kramer \& Willis, 2003; Lindenberger, Kliegl, \& Baltes, 1992). Regarding memory plasticity, the general finding is that older adults' plasticity is much more limited than that of younger adults but that cognitively 
healthy older adults, at least up to their 80 s, continue to be able to improve their memory performance through acquiring and using mnemonic techniques. Given that most adult memory-training studies had ensured that participants had relatively little preexperimental knowledge about the specific mnemonics under investigation, performance improvements after memory training can, in part, be interpreted as the beneficial effect of contextual support in the form of memory strategies (cf. Bjorklund, Miller, Coyle, \& Slawinski, 1997; P. H. Miller, 1990).

In the adult developmental literature, studies that applied a testing-the-limits paradigm by combining mnemonic instruction with extensive training have resulted in a differentiated picture of preserved gains and increasing losses. Older adults have shown sizeable baseline plasticity as indicated by performance improvements after initial mnemonic instruction. However, their developmental plasticity is reduced relative to younger adults, as indicated by limited training-induced performance gains (e.g., Baltes \& Kliegl, 1992; Baltes \& Lindenberger, 1988; Hill, Bäckman, \& Stigsdotter Neely, 2000; Kliegl, Smith, \& Baltes, 1989; Lindenberger et al., 1992). This aging-related reduction in developmental plasticity is particularly pronounced for individuals beyond the 8th decade of life (Singer, Lindenberger, \& Baltes, 2003).

Training studies also have played a prominent role in research on child cognitive development (see Stevenson, 1983, for an early review). The development of metacognitive skills, such as the emergence of implicit and explicit strategy representations, is known to interact with the development of basic information processing skills (e.g., see Flavell, 1992). In particular, studies on children's memory development have revealed the distinct contributions of strategy acquisition, spontaneous strategy use, and strategy effectiveness to changes in memory performance from early childhood to adolescence. In this context, strategy deficiency concepts have been proven helpful to characterize age differences in memory performance (see Bjorklund et al., 1997, for review). For instance, mediation deficiencies refer to children's problems in using mediators (e.g., verbal labels or strategies) to improve their recall performance (Reese, 1962). Production deficiencies refer to children's failures in generating strategies spontaneously, although they may be able to produce them when asked to do so (Flavell, 1992). Finally, utilization deficiencies refer to situations in which younger children are able to produce strategies spontaneously but do not benefit much from their application (P. H. Miller, 1990).

When the tripartite notion of plasticity proposed by Kliegl and Baltes (1987; Baltes, 1987) is compared with the strategy deficiency notions elaborated in the child developmental literature, a set of common questions can be noted. First, developmental differences in the efficacy of spontaneous strategy production are related to the concept of baseline performance. Baseline plasticity indicates the individual's memory improvement after mnemonic instructions have been provided. Thus, individuals who cannot spontaneously produce a strategy could benefit from exposure to an efficient strategy if opportunities for acquisition and practice suffice. Second, developmental differences in the efficiency of using mediators and utilizing memory strategies are more related to the concept of developmental plasticity, insofar as developmental plasticity reflects performance improvement due to optimized strategy implementation after extensive practice.

With careful instruction in age-appropriate strategies, even younger children can benefit and improve their performance on many tasks (e.g., Brainerd, 1974). However, in general, younger children usually require more intensive training than do older children to make effective use of task-relevant strategies (e.g., Pressley \& Levin, 1983; Rohwer, 1973). Likewise, reductions in information-processing demands tend to improve strategy use and thus memory performance (e.g., Schlagmüller \& Schneider, 2002).

Similar to the testing-the-limits approach favored in the adult developmental literature, microgenetic research designs have been used to examine the course of skill development in children (e.g., Kuhn, 1995; Siegler \& Crowley, 1991). In contrast to testing-thelimits procedures, in which individuals typically are instructed and trained in an experimenter-provided strategy, microgenetic studies primarily look at the nonmanipulated, natural course of strategy acquisition, selection, and refinement. Thus the emphasis is less on plasticity in performance with respect to specific strategies than on the developmental course and diversity of strategy acquisition (Schlagmüller \& Schneider, 2002; Siegler \& Crowley, 1991).

Taken together, training studies on child memory development have aimed at identifying the reasons why younger children cannot benefit as much from certain cognitive strategies as can older children or at comparing the efficiency of different types of strategy instruction. Recent conceptual frameworks in both child development (Cowan, 1997; Kuhn, 1995; Nelson, 2002; Ornstein \& Haden, 2001; Siegler, 2004) and aging (Cherry, Park, Frieske, \& Rowley, 1993; Dunlosky, Hertzog, \& Powell-Moman, 2005) emphasize the dynamic interplay between knowledge and information-processing mechanisms during cognitive development. Thus, memory plasticity in childhood, including comparisons with other periods of life, has become an important desideratum on the developmental research agenda.

\section{This Study}

Studies that contrast age differences during childhood and old age can shed light on the similarities and differences in fundamental mechanisms underlying the growth and decline of memory plasticity across the life span (cf. Craik \& Bialystok, 2006). However, direct comparisons of memory plasticity that range from middle childhood to old age have not been undertaken thus far. Hence, we investigated life-span age differences in episodic memory plasticity from middle childhood to early old age. Because there are sizeable maturational changes during middle childhood in cortical regions that support memory performance such as the prefrontal lobes (cf. Sowell, Thompson, Tessner, \& Toga, 2001), we included two groups of children (9-10 and 11-12 years of age). The data presented here are part of a larger project on neurophysiological correlates of successful episodic memory encoding and retrieval across the life span (for an overview, see Brehmer, Müller, von Oertzen, \& Lindenberger, 2004). This article focuses on behavioral training aspects and memory plasticity.

Informed by general tenets from life-span psychology (e.g., Lindenberger, 2000, Figure 1; cf. Baltes, 1987; Baltes et al., 2006; Denney, 1984) as well as previous findings on developmental differences in the effects of training on memory performance during childhood (e.g., Bjorklund et al., 1997; P. H. Miller, 1990; also see reviews above) and adulthood (Kliegl et al., 1989; Lindenberger, Mayr, \& Kliegl, 1993; Singer et al., 2003), this study tested three main hypotheses: 
Hypothesis 1: Individuals in all age groups will improve their episodic memory performance through mnemonic instruction and training and/or deliberate practice (henceforth referred to as practice), reflecting the presence of episodic memory plasticity during most periods of life.

Hypothesis 2: Memory plasticity will be larger among children than among older adults. Specifically, older adults will profit from initial mnemonic instruction in much the same way as younger individuals, as both adults and old adults have the advantage of broader knowledge and experiences, which aid the understanding of mnemonics. However, on the basis of previous findings showing that normal aging depletes memory-related developmental plasticity (e.g., see Verhaeghen, Marcoen, \& Goossens, 1992, for review), they will profit less from deliberate practice. Children, on the other hand, although they may not be as efficient in producing a memory strategy spontaneously (Flavell, 1992), once a given strategy and sufficient amount of practice are given, will be able to use the strategy to improve memory performance (Brainerd, 1974).

Hypothesis 3: In accordance with the magnification model of episodic memory performance (Kliegl et al., 1989; Verhaeghen et al., 1992), life-span age differences in episodic memory will be magnified after extensive practice relative to age differences at baseline (i.e., prior to mnemonic instruction and practice).

\section{Method}

\section{Study Participants}

The effective sample for this study consisted of 108 participants distributed over four age groups: 23 younger children (ages 9-10 years, $M=9.6$ ), 27 older children (ages $11-12$ years, $M=11.9$ ), 29 younger adults (ages 20-25 years, $M=22.5$ ), and 29 older adults (ages 65-78 years, $M=66.9$ ). Participants were paid 7.5 Euro (approximately U.S. \$8.40) per hr. Gender was almost equally distributed within each age group, resulting in a $4 \times 2$ (Age Group $\times$ Gender) design matrix with a minimum of 11 individuals in each cell. All participants were volunteers. The children in the study sample were either attending a Gymnasium (i.e., the school type with the highest entry requirements after completion of elementary school) or were still attending elementary school but had already been recommended by the school to attend a Gymnasium. The younger adults were students at Saarland University. The older adults were either auditors at Saarland University, participants in other continuing education programs, or both. The positive sampling across all age groups reduced possible confounds that are associated with general intellectual interests and abilities and, thus, increased the validity of age comparisons in episodic memory plasticity. At the same time, this feature of the study may reduce the generalizability of results to the general population.

Age differences in crystallized and fluid intelligence were also assessed by tests validated on life-span samples (Li et al., 2004; Lindenberger \& Baltes, 1997; Lindenberger et al., 1993). We found age differences comparable to previous findings in our sample. Specifically, verbal knowledge as an indicator of crystal- lized intelligence showed a steep increment from middle childhood to young adulthood, followed by stability from early to later adulthood (younger children: $M=37.8, S D=4.4$; older children: $M=42.8, S D=4.6$; younger adults: $M=57.5, S D=4.2$; older adults: $M=58.9, S D=4.2$ ). In contrast, perceptual speed, the primary indicator of fluid intelligence, showed a steep increment during middle childhood, with a peak in young adulthood and a continuous decline in old age (younger children: $M=43, S D=$ 5.4; older children: $M=46.2, S D=4.2$; younger adults: $M=$ 63.3, $S D=5.9$; older adults: $M=45.8, S D=7.2$ ).

In order to enhance the interpretability of neurobiological data not reported here, we included only right-handed individuals in the study. To ensure that the participants did not have preexperimental knowledge about memory strategies, we excluded psychology majors and individuals who were familiar with mnemonics from the sample. Furthermore, individuals ( 9 younger children, 2 older children, and 4 older adults) with a score of 34 or less on the Digit Symbol Substitution test (DSS) of the Wechsler Adult Intelligence Scale (Wechsler, 1958) were excluded from the study. The DSS score was of relevance because earlier studies on memory plasticity in adulthood and old age showed that individuals with DSS scores below values of around 35 are unlikely to fully acquire and appropriately use mnemonic techniques (Kliegl et al., 1989; Singer et al., 2003; Annette Rentz, personal communication, September 2002). The magnitude of this experimental selectivity can be evaluated in terms of effect-size estimates that were computed directly as the normed difference between the selected sample and the parent (initial) sample (i.e., effect size of selectivity = $M_{\text {select }}-M_{\text {parent }} / S D_{\text {parent }}$; for details, see Lindenberger, Singer, \& Baltes, 2002). The positive selection bias for DSS scores was moderate in younger children (0.45) and small among older children (0.16) and older adults (0.20). However, individuals excluded because of low DSS performance did not differ from the rest of the age groups on three psychometric tests of episodic memory administered at baseline (effect sizes were smaller than 0.2 for these tests). Thus, though the younger children in our sample were somewhat more positively selected on perceptual speed than were participants in the other age groups, no age group differences in sample selectivity were observed for baseline measures of episodic memory.

The effective sample was further reduced by excluding (a) individuals who did not complete all training sessions because of scheduling conflicts ( 7 younger children, 2 older children, 5 younger adults, and 3 older adults); (b) individuals who dropped out because of health reasons ( 1 younger adult and 3 older adults); and (c) 5 younger children who failed to acquire the mnemonics after extensive instructions. These 5 children achieved an average correct recall level of 39.6 items in the posttraining session with $14 \mathrm{~s}$ of encoding time, as compared with this group's mean of 56.9 recalled items with $2.8 \mathrm{~s}$ of encoding time. We are aware that excluding the 5 outliers from the younger children's group enhanced the positive selection for this group. However, control analyses showed that the age by session interaction that is critical for the findings reported below remained statistically significant when the 5 children who apparently did not learn the mnemonic technique were not excluded from the analysis, $F(1,106)=12.1$, $p<.05, \eta^{2}=.10$. Moreover, the 5 children who were excluded from the sample did not differ reliably from the other children on any of the intellectual ability measures administered at pretest. 


\section{Memory Materials and Imagery Mnemonic}

We used location-word pairs to assess episodic memory performance. In order to minimize age differences in preexperimental familiarity of the location cues, we used 16 generic common city locations, such as a bakery and train station, as landmark cues (for a complete list of the 16 location cues, see Brehmer, Müller, et al., 2004). The 16 locations were used across different lists and sessions, each time with a different random order. As for the to-berecalled words, a total of 413 highly imaginable, concrete nouns were selected as memory material from an original pool of 1,082 nouns recorded by a professional broadcasting speaker (see Singer et al., 2003, for a description of the word pool). To reduce possible confounds of age differences in memory performance with age differences in word knowledge, we selected words in a separate small-scale rating study with a two-step procedure. First, 10 children ages 7-9 years rated a subsample of the original word pool on a 3-point scale of comprehensibility, and only the most comprehensible words were retained. Second, two independent raters further selected words to reduce the likelihood of lexical errors during recall (for additional details, see Brehmer, Stoll, et al., 2004).

Each study list consisted of 16 location-word pairs. No word was administered more than once within a given session. Words were recycled across the sessions with the following three constraints: (a) A word presented at a given session did not reappear in the next session; (b) within each list, we ensured that the first three letters of all 16 words were different from each other to minimize errors during response entry (see below); and (c) words presented in the sessions for assessing preinstruction baseline performance and postinstruction performance were not presented in any other session. ${ }^{1}$

\section{Imagery Mnemonic: Modified Method of Loci}

Throughout the entire experiment, the presentation order of location cues during mnemonic training and testing was randomized separately for encoding and retrieval phases. This procedure differs from standard variants of the method of loci (e.g., Bower, 1970; Yesavage \& Rose, 1984), which use an invariant sequence of locations to preserve the serial order of the memory list. The rationale for this modification was twofold: (a) to reduce the contribution of individual and age differences in the ability to accurately and swiftly retrieve serial order information from longterm memory (e.g., Brown, Vousden, McCormack, \& Hulme, 1999; Kausler, 1994) to episodic memory performance; and (b) to maximize the relative contribution of associative processing (e.g., feature binding) at the level of individual location-word pairs to successful recall (cf. Werkle-Bergner, Müller, Li, \& Lindenberger, 2006).

\section{Experimental Procedure}

Encoding phase. During encoding, location cues were presented visually on a monitor, and the to-be-recalled words were presented auditorily over headphones. Depending on the amount of encoding time (i.e., longer or shorter than $10 \mathrm{~s}$ ), the location cue was presented on the screen for either 2 or $0.5 \mathrm{~s}$, respectively. For preinstruction, instruction, and postinstruction sessions, the encod- ing times of to-be-learned words were set to $10 \mathrm{~s}$. During the individualized deliberate practice sessions, an adaptive algorithm adjusted encoding times individually for each participant at the list level (see the section on experimental sessions for details). At the final posttest, we assessed postpractice memory performance using individualized encoding times.

Recall phase. Participants started the recall phase by pressing the space bar. An empty screen then appeared for $500 \mathrm{~ms}$, followed by a location cue, which was presented for 5,000 ms. Following the location cue, a blue rectangle appeared on the screen to show the participants that they could respond by typing the first three letters of the corresponding word. Participants were allowed to correct their responses by using the backspace key. Within each list, the first three letters of all 16 words were different from each other; this helped to avoid errors during response entry. This recall scheme was developed mainly to minimize the influences of individual differences in spelling ability on the assessment of individual differences in episodic memory performance (see Brehmer, Müller, et al., 2004, for details of the computer program that scored the performance by searching for the closest match between a response and all words presented in the list).

\section{Description of Experimental Sessions and the Adaptive Practice Algorithm}

Table 1 summarizes the various sessions of the study. Prior to the experiment, participants were administered a demographic questionnaire, followed by a psychometric battery of 12 tests assessing four broad domains of intellectual abilities (i.e., perceptual speed, reasoning, memory, and verbal knowledge). Standard measures of visual and auditory acuity were also administered (for detailed information on the psychometric properties of these tests, see Li et al., 2004; Lindenberger \& Baltes, 1997). The different phases of the memory training experiment are presented below. Training included both instruction and practice (cf. Ericsson, Krampe, \& Tesch-Römer, 1993).

Baseline memory performance session. In the first experimental session, individuals were asked to encode and later recall four lists of 16 words each to assess baseline memory performance. Numbers ranging from 1 to 16 were used as cues during encoding and retrieval for the first two lists, whereas the 16 location cues described above were used for the latter two lists as well as for the rest of the experiment. The reason for including both number and location cues was to provide more than one type of preinstruction

\footnotetext{
${ }^{1}$ Because of a technical error, some words in the posttraining session had been presented in earlier sessions but at different locations, with a few exceptions. The number of words presented at earlier sessions varied as a function of the number of training sessions needed to reach criterion performance. We conducted control analyses to examine the potential influence of word familiarity on age group comparisons at posttest. Younger children and older adults needed six sessions of training (maximum number of sessions) more often than did older children and younger adults. Younger children and older adults had greater prior exposure to words presented at the postpractice session than had older children and younger adults, $F(1,104)=10.97, p<.05, \eta^{2}=.095$, but did not differ between each other, $F(1,104)=0.80, p>.05$. Results did not change when the number of words presented at prior sessions was included as a covariate in the analyses presented in this article.
} 
Table 1

Overview of the Study Design

\begin{tabular}{lcc}
\hline \multicolumn{1}{c}{ Study phase } & Session (no.) & $\begin{array}{c}\text { Session } \\
\text { duration (hr) }\end{array}$ \\
\hline $\begin{array}{l}\text { Assessments of general demographic } \\
\quad \text { information, psychometric }\end{array}$ & & \\
$\quad$ intelligence, visual and auditory & 1 & $\sim 2$ \\
$\quad$ acuity & 1 & $\sim 2$ \\
$\begin{array}{l}\text { Preinstruction baseline memory } \\
\quad \text { assessment }\end{array}$ & & \\
$\begin{array}{l}\text { Instruction and initial training of } \\
\quad \text { memory mnemonics }\end{array}$ & 2 & $\sim 1$ \\
$\begin{array}{l}\text { Postinstruction assessment } \\
\text { Adaptive practice to criterion }\end{array}$ & 1 & $\sim 2$ \\
Postpractice assessment & $2-6$ & $\sim 1$ \\
\hline
\end{tabular}

Note. Individuals differed in the number of adaptive practice sessions (2-6) required to achieve asymptotic level of performance during practice.

baseline when we were assessing performance gain after mnemonic instruction and practice. The analyses reported below refer to baseline performance on the two lists with location cues.

Mnemonic instruction sessions. In the next two sessions, participants were introduced to the mnemonic technique. The first mnemonic instruction session took place in age-homogeneous groups of 3 to 4 individuals. We explained the principles of method of loci with concrete examples, emphasizing the generation of interactive, dynamic images or thoughts that associate a given location cue with the to-be-remembered word. Participants then practiced the technique with two word lists on computers individually. In all later sessions, six lists of 16 words each were administered per session. Instruction and supervised training were continued individually in a second instruction session. To familiarize the participants with the mnemonic technique, we used prompts to verbalize and discuss all aspects of image formation, image retrieval, and image generation, assistance during recall, repetition and elaboration of instructions, as well as various other forms of encouragement.

Postinstruction assessment. We tested memory improvement after the two mnemonic instruction sessions in a single postinstruction session to assess memory performance gain after instruction that indicated baseline plasticity. In this session, participants performed the episodic memory task using the mnemonic technique without any assistance from the experimenter.

Individualized adaptive practice sessions. Individual training sessions started after the postinstruction assessment. The encoding times were adjusted individually so that all individuals practiced the mnemonic skill at comparable levels of difficulty (see the section on the adaptive practice algorithm for details). Individualized practice lasted for two to six sessions, depending on the number of sessions needed for each of the participants to reach an asymptotic level of episodic memory performance defined by the adaptive practice algorithm. In general, individuals participated in one or two sessions per week, with a minimum of 2 days between sessions to minimize proactive interference across sessions (e.g., Kliegl \& Lindenberger, 1993). Practice sessions took place in groups of 2 to 5 individuals. Individuals in these groups practiced the task on separate computers at an individualized pace and without any further strategy-relevant assistance from the experi- menter. During individualized deliberate practice, adjustments in encoding times were used to adjust task difficulty adaptively for each participant to a fixed recall criterion of $62.5 \%$ correct recall (cf. Kliegl \& Lindenberger, 1993). A recall level of $62.5 \%$ was considered appropriate as a criterion level for adaptive practice because participants experienced this level as sufficiently high to demonstrate the utility of the instructed strategy and motivate further practice. At the same time, this level was sufficiently low to safeguard against ceiling effects. Specifically, for each individual, the adaptive algorithm determined the amount of encoding time per word for the next list on the basis of the following four variables: number of correctly recalled words of the current list, encoding time of the current list, the current step width, and the direction (i.e., increase, decrease, or equal) of adjustment. We updated these adaptive training variables after each list to maximize the likelihood that a given individual would correctly recall 10 out of 16 words in the next list during practice (see Brehmer, Müller, et al., 2004, for details about the algorithm). The practice phase ended when either of two conditions was met: (a) The step width for the next list was lower than $0.08 \mathrm{~s}$, indicating that asymptotic level of performance had stabilized at a given encoding time and accuracy level, or (b) individuals completed the maximum of six practice sessions.

Postpractice assessment. In a final single session, performance levels after multiple sessions of individualized deliberate practice were assessed with six lists at individualized encoding times reached at the last adaptive practice session.

Time elapsing between sessions. Attempts were made to ensure that the time elapsing between sessions did not vary considerably across age groups. The time between mnemonic instruction and postinstruction sessions did not exceed 1 week, and the average time elapsing between these two sessions did not differ across age groups, $F(3,104)=1.14, p=.34$. The same was true for the time elapsing between the last practice session and the postpractice session, $F(3,104)=2.23, p=.09$.

Performance feedback. For motivational reasons, after recall of each list, participants were given feedback about their level of recall performance. In the preinstruction, postinstruction, and postpractice sessions, feedback consisted of the number of correctly recalled items and the rate at which words had been presented at encoding (e.g., 5 out of 16 items correct, encoding time $6,000 \mathrm{~ms}$ per word). During instruction and adaptive practice, performance feedback was supplemented by item-specific information. Participants were presented a table listing the following: (a) the serial position of each word at encoding, (b) the serial position of each word at recall, (c) the corresponding location cue, (d) the correct word, (e) the letters entered by the participant and the word that the program had assigned to these letters, and (f) finally, a letter stating whether this word was recalled correctly ( $R$ for German richtig) or incorrectly ( $F$ for German falsch). Furthermore, a reward feedback of relative performance across lists was presented as a line drawing of a smiley face. Participants saw the smiley face when the following two conditions were met: (a) They had correctly recalled six or more words from the list, and (b) their performance was better than in the previous list. Additionally, when a participant broke his or her highest performance record, he or she received a smiley face together with congratulations for having attained a higher score. Pilot studies showed that this 
feedback regime was effective in keeping the participants motivated within and across sessions.

\section{A Priori Contrasts of Life-Span Differences in Memory Performance}

We defined three orthogonal a priori contrasts to investigate our guiding hypotheses about life-span differences in episodic memory. We assumed that younger children and older adults would probably show lower memory performance compared with older children and younger adults, reflecting life-span trajectories of basic cognitive processes (e.g., Li et al., 2004; McArdle, FerrerCaja, Hamagami, \& Woodcock, 2002). Therefore, the first contrast specified a comparison of the two extremes of the life span (younger children and older adults) against the two other age groups (older children and younger adults). To compare the effects of maturational and aging-related processes in episodic memory performance with different aspects of memory plasticity, we used the second contrast to compare the two extremes of the life span as represented in this study against each other, that is, younger children versus older adults. The third contrast tested whether older children differed in performance from younger adults. In addition to these three a priori orthogonal contrasts, direct comparisons between the two child groups were added post hoc if needed. For all analyses, alpha levels were set to .05. Reported effect sizes refer to partial eta-squared values. Whenever variance homogeneity assumptions were violated, Greenhouse-Geisser adjustments were made and similar patterns of results were found, unless reported otherwise.

\section{Results}

\section{Overview of Analyses}

In the following, we first present descriptive results on the average number of practice sessions the participants needed to reach the experimentally defined performance criterion. Performance in the postpractice session is next presented separately for encoding time and accuracy. The main analyses of life-span age differences in different levels of episodic memory plasticity are examined with respect to the timed recall score (see below for details about this measure), comparing preinstruction, postinstruction, and postpractice performance. Thus, statistical analyses are preceded by descriptive information regarding this score. Individual performance levels will be examined in a final section.

\section{Number of Training Sessions to Reach Performance Criterion}

Figure 1 shows (a) the distribution of the number of practice sessions across the four age groups and (b) the number of individuals within each age group who failed to reach criterion within 6 sessions of practice. On average, the number of practice sessions needed to reach the adaptive criterion differed by age, $F(3,104)=$ $4.4, p<.05, \eta^{2}=.11$. Younger adults needed an average of 4 practice sessions, whereas older children, older adults, and younger children needed 4.4, 4.7, and 5 sessions, respectively. Older children and younger adults needed fewer practice sessions in comparison to younger children and older adults, $F(1,104)=$ $10.51, p<.05, \eta^{2}=.09$. However, the groups at the two extremes of life span (younger children and older adults) did not differ, $F(1$, $104)=0.76, p>.05$, nor did the two groups at the middle of life span differ, $F(1,104)=2.1, p>.05$, in the number of practice sessions required to reach the performance criterion.

Thirty-five percent of the younger children, $19 \%$ of the older children, $10 \%$ of the younger adults, and $28 \%$ of the older adults did not converge to a stable level of memory performance according to the criterion specified by the adaptive algorithm (see section on individualized adaptive practice). The age groups differed in the likelihood of not reaching stable performance. More specifically, the likelihood of not reaching stable performance was found when

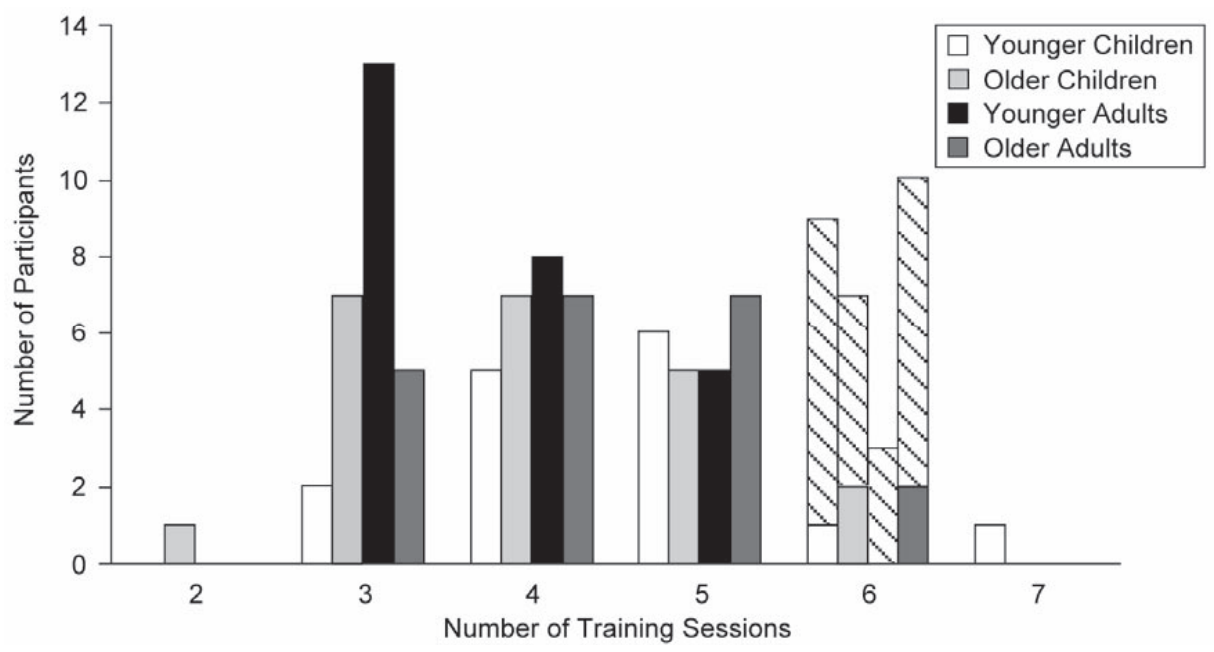

Figure 1. The number of training sessions as a function of age group. Training was terminated after six sessions regardless of whether performance asymptotes had been reached. Because of a scheduling error, one younger child participated in seven training sessions instead of six. All research participants with fewer than six sessions of practice reached an asymptotic level of performance. The number of participants who did not reach this asymptote in the sixth session is highlighted in hatched columns. 
we compared the two groups at the extremes with the two groups in the middle of the life span. Older adults and younger children were less likely to reach stable performance than were younger adults and older children, $\chi^{2}(1, N=108)=4.2, p<.05, \eta^{2}=.20$. Importantly, however, participants who reached stable performance did not differ in their postpractice memory performance from participants who did not, $F(1,107)=0.81, p>.05$.

\section{Age Differences in Postpractice Performance}

At postpractice assessment, encoding times were adjusted to maximize the likelihood that a given individual would correctly recall an average of 8 out of 16 words in each of the six lists. We chose this $50 \%$-correct criterion mainly to optimize the statistical power of subsequent memory analyses that was central for the larger neuropsychological study of life-span differences in neural correlates of successful encoding, a context in which the behavioral assessments reported here were embedded. We computed the encoding time for the final session by first dividing the average encoding time by the average number of correctly recalled items for each of the six lists of the last practice session and then multiplying this score by eight.

We first report descriptive statistics of overall age group differences in postpractice performance separately for encoding time and the number of correctly recalled items. Figure $2 \mathrm{a}$ displays individually adapted encoding times at the postpractice session. Each of the participants is represented by a symbol assigned according to his or her corresponding age group. Age groups differed regarding the amount of encoding time at postpractice, $F(3,104)=17.6, p<.05, \eta^{2}=.34 .^{2}$ On average, younger adults required $1,177 \mathrm{~ms}$ to correctly recall 10.3 words per list. Older children took on average 2,085 ms to recall 9.5 words, younger children took $2,856 \mathrm{~ms}$ to recall 9.5 words, and older adults took $4,052 \mathrm{~ms}$ to recall 8.7 words per list. Between-person variability in encoding times required to approximate the 50\%-correct criterion differed across age groups [Levene's test: $F(3,104)=10.7, p<$ .05]. Individual differences in the encoding time were largest among older adults $(S D=2,058 \mathrm{~ms})$ and younger children $(S D=$ $1,799 \mathrm{~ms}$ ), followed by older children ( $S D=1,533 \mathrm{~ms}$ ), who also showed substantial between-person encoding time variability, whereas younger adults showed much less between-person variability $(S D=266 \mathrm{~ms})$.

As a manipulation check of the individualized adaptive practice procedure, Figure $2 \mathrm{~b}$ displays the number of correctly recalled words as a function of encoding time at the postpractice assessment by age group. Overall, the number of words recalled did not vary systematically with encoding time, $r(108)=-.18, p>.05$, suggesting that the individualized adaptive practice algorithm worked equally well at different levels of encoding time. Nevertheless, the number of correctly recalled items differed across groups, $F(3,104)=7.1, p<.05, \eta^{2}=.17$. On average, younger and older children recalled $59 \%$ of the items correctly, whereas younger and older adults recalled $65 \%$ and $54 \%$ of the items correctly, respectively. Post hoc Scheffé tests showed that the age difference in accuracy was mainly due to the difference between younger and older adults (mean difference $=9.9$ correctly recalled items, $p<.05) .^{3}$

\section{Age Differences in Episodic Memory Plasticity}

To evaluate life-span age differences in episodic memory plasticity, we compared timed recall scores across preinstruction, postinstruction, and postpractice sections. Before we present the statistical analyses of age differences in the different levels of plasticity, we first describe this score, which combines recall accuracy and encoding time. Figure 3 displays individual learning curves for one 9-year-old child, one 12-year-old child, one young adult (e.g., 20 years of age), and one older adult (e.g., 67 years of age). The 4 selected individuals were typical in the sense that their encoding times during the postpractice session were close to the median of their age group. The plots depict the relation between encoding times and recall performance in the course of mnemonic instruction and individualized practice sessions. Results from preinstruction, postinstruction, and postpractice sessions are highlighted. Encoding times (i.e., black solid line) were held constant at a rate of $10 \mathrm{~s}$ per word during the first three sessions and then varied as a function of the adaptive algorithm. In the final session after practice, encoding times were fixed individually to a rate aiming for an average recall level that is close to the prespecified performance criterion (see section on encoding phase in experimental procedures). The 4 individuals differed in (a) the number of training sessions needed, (b) levels of recall, and (c) required encoding times.

The illustrative examples of individual learning curves highlight the challenges in interpreting and comparing performance across age groups. Recall performance differed and evolved dynamically as a function of adaptive practice, which differed across individuals and age groups. The general underlying assumption was that longer encoding times provide more opportunity for forming elaborate location cue-word associations. At the same time, individuals of different ages differ in the amount of time needed to form elaborate associations. Thus, in order to arrive at an indicator of memory performance that also takes into account within-person variations and between-person differences in encoding time during the course of adaptive practice, we combined the individual's recall accuracy and encoding time into a combined timed recall score. The general purpose of this score (see Equation 1) was to express correct recall over encoding time (cf. Kliegl, Mayr, \& Krampe, 1994). Thus, for each list, the number of correctly recalled items was divided by the encoding time at which the study items were presented. As the four age groups differed in the range of encoding times they needed for achieving the fixed accuracy level (for details, see data presented in Figure 2a), encoding times were $\log$ transformed to adjust for age group differences in processing speed. Because encoding time was fixed at $10 \mathrm{~s}$ during the preinstruction, instruction, and postinstruction sessions, the fixed

\footnotetext{
${ }^{2}$ Variance homogeneity assumptions were violated. Results stayed the same when they were analyzed nonparametrically, $\chi^{2}(3, N=108)=$ 51.99, $p<.05$.

${ }^{3}$ In terms of verifying the successful acquisition of the mnemonic memory technique, we examined recall level as a function of the serial position of to-be-learned words during encoding for both preinstruction and postpractice sessions. Primacy and recency effects were greatly attenuated in all age groups at the postpractice session, which supports the claim that participants in all age groups made use of the instructed strategy (cf. Roediger, 1980).
} 


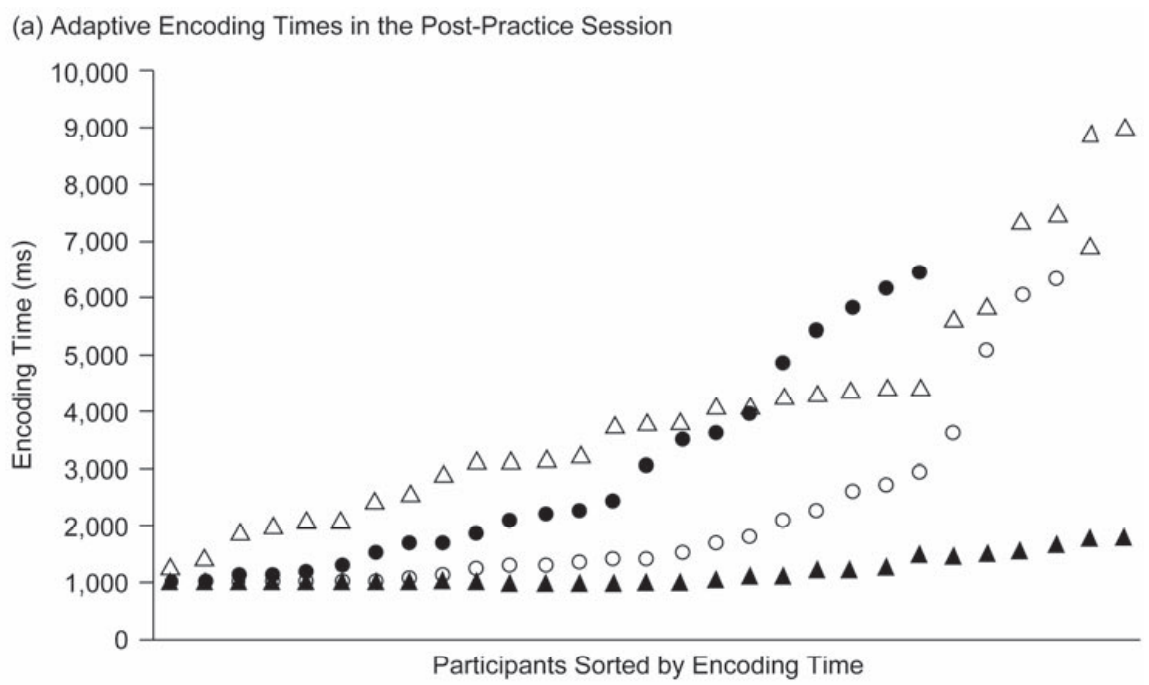

(b) Correct Recall in the Post-Practice Session

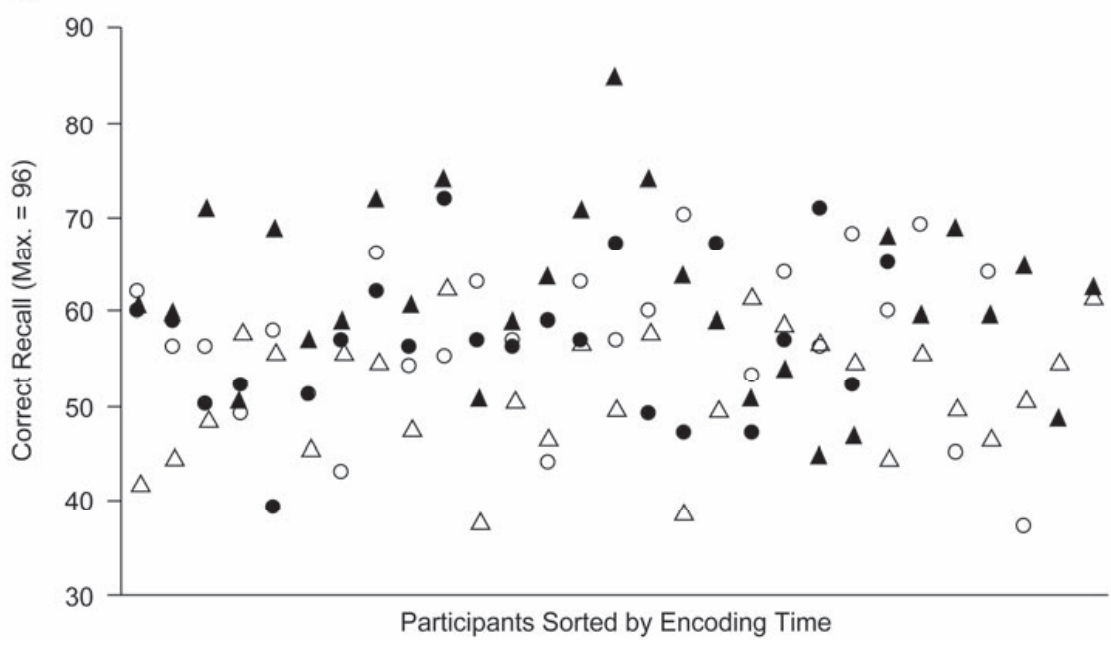

Figure 2. (a) Adaptive encoding times in the postpractice session. Each participant is marked by one symbol (solid circle $=$ younger children; open circle $=$ older children; solid triangle $=$ younger adults; open triangle $=$ older adults). Interindividual differences were largest among younger children, followed by older adults, older children, and younger adults, who showed little interindividual variability. (b) Correct recall in the postpractice session. Every participant is marked by one symbol. Participants are sorted by encoding times in ascending order. Encoding times and recall levels were not correlated across individuals.

coefficients of the natural $\log$ in Equation 1 were chosen to keep the metric of the scores constant between these sessions and the adaptive practice sessions.

$$
\frac{\sum_{i=1}^{n} \frac{c_{\mathrm{i}}}{\ln \left(1+\frac{e t_{\mathrm{i}}}{1000}\right)} \cdot \frac{\ln (11)}{10}}{n}
$$

Whereas younger children, older children, and older adults did not differ in baseline performance assessed in the preinstruction session, younger adults showed higher baseline memory performance, $F(3,101)=17.99, p<.05, \eta^{2}=.35$. The main results of episodic memory plasticity are presented in Figure 4. Results were analyzed by repeated measure, mixed factor analyses of variance with age group (four levels) and memory intervention (three levels) as within-subject factors. The main effect of memory intervention was significant, $F(2,100)=282.8, p<.05, \eta^{2}=.85$, reflecting that performance increased from preinstruction to postinstruction to postpractice sessions. The main effect of age group was also significant, $F(3,101)=53.6, p<.05, \eta^{2}=.61$, as well as the Age Group $\times$ Memory Intervention interaction, $F(6,202)=19.3, p<$ $.05, \eta^{2}=.37$. The four age groups differed in their performance and performance gain after mnemonic instruction and practice. Unfortunately, the relative difference in instruction and practice- 

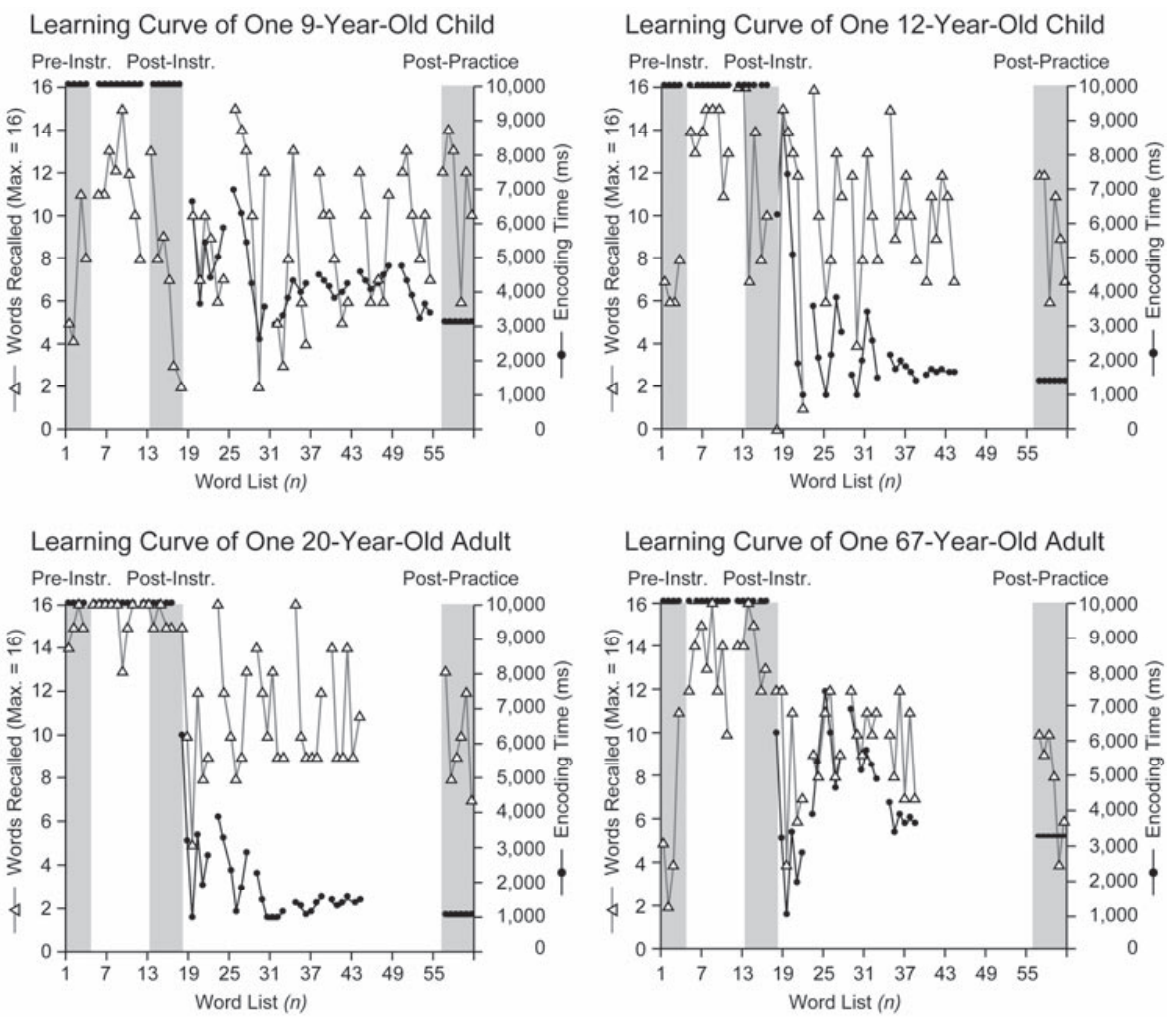

Figure 3. Learning curves of 4 different participants (9-year-old child, 12-year-old child, 20-year-old student, 67 -year-old senior). Gray dotted lines refer to the number of correctly recalled words per list, and black solid lines refer to encoding times. Preinstruction, postinstruction, and postpractice sessions are highlighted in gray.

related performance gains could not be discerned unequivocally in younger adults because ceiling effects dampened their postinstruction scores (i.e., average correct recall in this group was 15.5 out of 16 words). We expected the older children to have the highest developmental plasticity in comparison with all other age groups. Younger children improved their memory performance after instruction to the same extent as older adults, $F(1,101)=1.49, p>$ $.05 .^{4}$ However, younger children profited more from multiple sessions of practice than did older adults, $F(1,101)=24.3, p<$ $.05, \eta^{2}=.20$. Thus, younger children showed similar baseline but more developmental memory plasticity than did older adults.

Comparing the two groups of children, we found no significant differences in instruction gain, $F(1,47)=0.4, p>.05$, and practice gain, $F(1,48)=2.2, p>.05 .{ }^{5}$ When data were collapsed across the two child groups, the results of comparisons between this combined child group and older adults were similar to the results when just the younger children were compared with the older adults. Again, instruction gain did not differ between the groups, $F(1,102)=1.79, p>.05$, but practice did because children showed greater gains than did older adults, $F(1,102)=$ 51.1, $p<.05, \eta^{2}=.33$.

\section{Descriptive Analyses of Episodic Memory Plasticity at the Individual Level}

To further examine the relative contribution of instruction and practice to performance improvements, we partitioned posttest (overall training) performance into baseline performance, instruction gain, and practice gain for young children, older children, and older adults, as shown in Figure 5. Given that instruction and practice gains could not be differentiated in younger adults because of the ceiling effect in the postinstruction session, performance improvements in members of this group were partitioned into baseline performance and overall training gain, which comprised both instruction and training. Within each of the age groups, participants were sorted by baseline performance. Seventeen of the 23 younger children (74\%) and 25 of the 27 older children (92\%) showed greater gains during practice than after instruction, whereas 20 of the 29 older adults $(69 \%)$ showed the opposite pattern, $\chi^{2}(2, N=108)=25.8, p<.05, \eta^{2}=.58$. In addition, the memory performance of 4 older adults actually decreased rather than improved from postinstruction to postpractice. These analyses

\footnotetext{
${ }^{4}$ Variance homogeneity assumptions were not met. The analyses were also performed on rank-transformed data. Results changed, $F(1,101)=$ $4.75, p=.032, \eta^{2}=.04$, in the sense that older adults improved more through instruction than did younger children.

${ }^{5}$ Instruction gains were calculated as the difference between Lists 3 and 4 of the preinstruction session, in which locations were used as cues, and Lists 3 and 4 of the postinstruction session. Training gains were calculated as the difference between all six lists of the postinstruction and all six lists of the posttraining session.
} 


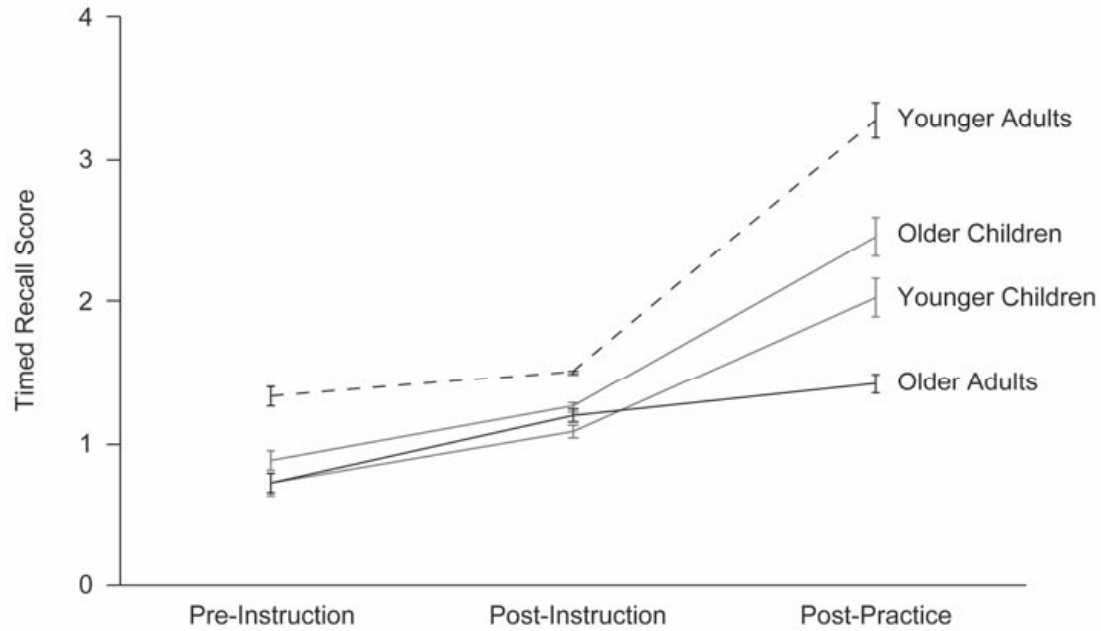

Figure 4. Life-span age differences in memory plasticity. The timed recall score is a ratio of correctly recalled items over encoding time, $c i / \ln (1+e t / 1000) \cdot(\ln 11) / 10$. Postinstruction scores for younger adults cannot be interpreted because of ceiling effects; all other data points can be interpreted. Error bars represent standard errors.

at the individual level corroborate the results observed at the level of group means.

\section{General Discussion}

\section{Summary of Findings}

The primary aim of this study was to investigate life-span age differences in episodic memory plasticity. Individuals in all age groups showed substantial improvement in memory performance as a function of instruction and training. This is consistent with the hypothesis that memory plasticity is present throughout the age period from middle childhood to early old age. At the same time, marked age group differences in the three components of memory plasticity emerged. Memory performance at baseline was highest in younger adults; the average baseline performance of younger children, older children, and older adults was substantially lower and did not differ between the three groups. Younger adults also showed the greatest amount of developmental plasticity, as indicated by the largest gains in memory performance as a function of instruction and training. The two groups of children and the group of older adults did not show a reliable difference in their amount of baseline plasticity, as indexed by comparable gains in perfor-
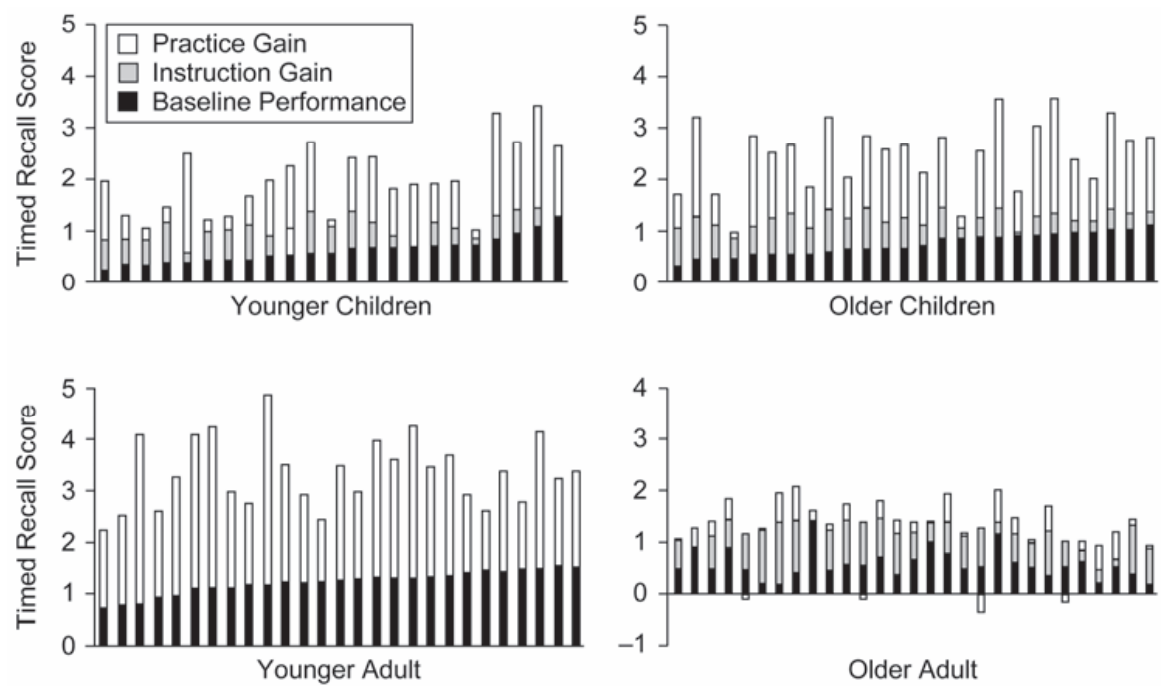

Figure 5. Individual instruction gains and practice gains as a function of age group. Baseline performance is marked in black, instruction gain is marked in gray, and practice gain is marked in white. Each column represents one individual. Individuals are sorted by encoding time in ascending order. Training gains of younger adults cannot be separated into instruction gains and practice gains because of ceiling effects in the postinstruction session. 
mance after mnemonic instruction. However, the two child groups profited considerably more from memory training than did older adults. This finding is consistent with the hypothesis that developmental plasticity in episodic memory functioning is larger in middle childhood than in old age. Neither in terms of instruction gains nor with respect to practice gains did the two child groups differ significantly from each other. Finally, and in line with our third hypothesis (cf. Baltes, 1987), shifting the context of measurement from baseline levels (preinstruction assessment) over baseline plasticity (postinstruction assessment) to the assessment of developmental plasticity (postpractice assessment) resulted in a massive increase of age-associated differences in performance levels (see Figure 4).

In addition to between-age group differences in upper limits of episodic memory performance, we observed substantial interindividual differences within age groups (see Figure 5). Again in line with earlier predictions (Baltes et al., 2006), it is interesting to note that these differences increased further, rather than decreased, when individuals performed closer to their upper limits of performance potential. Results found for the group of younger children are especially remarkable in this regard. Among these children, posttraining encoding times needed to correctly recall approximately $59 \%$ of the to-be-learned words ranged from $1 \mathrm{~s}$ to $7.2 \mathrm{~s}$ $(M=2.9, S D=1.9)$, or a factor of 7 ! Most likely, these interindividual differences reflect a combination of interindividual differences in the speed of cortical maturation as well as stable interindividual differences in relevant intellectual abilities. Regardless of its precise etiology, the presence of such massive differences in developmental plasticity among children of the same age has important applied implications. For instance, any form of school instruction based on the premise of performance homogeneity within age groups is doomed to failure under such conditions.

\section{Age Differences in Baseline and Developmental Plasticity of Episodic Memory: Toward the Separation of Strategic and Associative Components}

Episodic memory is often decomposed into various components or functions (Craik, 2006). One common distinction refers to strategic and associative components (e.g., Prull, Gabrieli, \& Bunge, 2000). The strategic component of episodic memory refers to the selection, organization, evaluation, and elaboration of episodic features during encoding and retrieval. Elaboration and organization may occur spontaneously or can be elicited by instruction and practice. The involvement of the strategic component is generally less pronounced during recognition than during free recall, reflecting differences in the relative importance of implicit and explicit processes (e.g., familiarity and recollection). Similarly, the retrieval of contextual features such as source memory, list discrimination, frequency judgments, and memory for order is generally aided by recollection and is more open to strategic influence. The associative component of episodic memory refers to the generation and retrieval of links (e.g., associative connections) between different features of a memory item, between different memory items, or between a given memory episode and its context (e.g., Li, Brehmer, Shing, Werkle-Bergner, \& Lindenberger, 2006; Naveh-Benjamin, 2000). This component reflects binding mechanisms that are active during the encoding, storage, and retrieval of information.
Strategic and associative aspects of episodic memory are conceptually separable but closely interact in the course of episodic memory formation and retrieval (E. K. Miller \& Cohen, 2001; Stuss \& Alexander, 2005). Therefore, dissociations between associative and strategic components of episodic memory are hard to obtain. Life-span comparisons may offer valuable insights, as differences between the ontogenetic paths of the two components may help to gauge the relative contributions of strategic and associative processes to episodic memory performance.

Specifically, Baltes's (1987) distinction between baseline and developmental plasticity is well suited for examining lifespan age differences in strategic and associative aspects of episodic memory, respectively. The first phase of the intervention procedure assessed the baseline memory plasticity of individuals by providing additional contextual resources, in the specific form of a mnemonic strategy, to enhance memory performance. The second phase assessed individuals' developmental plasticity by providing a context for intensive, deliberate practice aimed at optimizing the ability of individuals to execute the mnemonic strategy, which critically required the formation of memorable associations between location-noun pairs. According to this interpretation, instruction gain (i.e., performance gain after initial mnemonic instruction) indicates the current ability of individuals to make use of the newly learned mnemonic strategy to actively organize (or categorize) the to-be-remembered memory materials. Thus, instruction gain primarily reflects developmental and individual differences in the strategic component of episodic memory. On the other hand, practice gains indicate individuals' latent potential in finetuning mechanisms involved in the execution of the mnemonic strategy for optimizing the formation and retrieval of new associations. Hence, practice gain may reflect developmental and individual differences in the associative component of episodic memory more than differences in the strategic component.

In the current study, younger children did not benefit more than older adults from being instructed to use a mnemonic strategy; in fact, there was a trend in the opposite direction, $F(1,101)=3.10$, $p=.08$. However, younger children profited much more than older adults from subsequent practice. The optimization of strategy execution is an important factor for learning in childhood (e.g. Ornstein \& Haden, 2001; Schlagmüller \& Schneider, 2002; Siegler, 2004). Thus, the present findings may suggest that children in middle childhood and cognitively healthy adults in early old age do not differ much in their potential for improving the strategic component of episodic memory but that children show more plasticity in the associative component.

\section{Relations to Earlier Research in Cognitive Child Development and Cognitive Aging}

In research on memory development in children, inefficient strategic behavior in young children has been linked to deficiencies in mediation, production, and utilization (see Bjorklund et al., 1997, for a review). These deficiencies also serve as candidate mechanisms for explaining age-related and experience-related improvements in strategic aspects of memory performance. The present study was not designed to distinguish between these various sources of age-associated differences in strategic behavior. 
Instead, participants in all age groups were trained in a specific mnemonic memory strategy deemed to be effective over the age range included in this study. For instance, we did not investigate the kinds of strategies the individuals would spontaneously use or generate, as would be appropriate to examine age differences in production deficiency (Bjorklund et al., 1997). Nevertheless, the differences between baseline performance and postinstruction performance as observed in the present study may reflect, to some degree, age differences in production deficiency. Furthermore, training is known to shape effective utilization of memory strategies in children (e.g., P. H. Miller, 1990). Remaining age differences in postpractice performances may reflect utilization deficiencies, in the sense that young children and older adults failed to use an instructed and trained strategy as efficiently as did young adults.

Cognitive aging researchers have also invoked different strategic (e.g., mediator-based) deficiencies to account for age differences in episodic memory performance (e.g., Dunlosky et al., 2005; Hulicka \& Grossman, 1967; Kausler, 1994; Nyberg, 2005; Treat \& Reese, 1976). Recently, Dunlosky et al. (2005) examined and discussed the relative importance of these various deficiencies. Interestingly, their results suggest that neither mediation, nor production, nor utilization deficiencies at encoding alone are likely candidates for explaining older adults' associative memory deficits (see also Dunlosky \& Hertzog, 1998). Instead, such deficits are more likely to reflect differences in the abilities (a) to recall the mediators generated at encoding and (b) to efficiently use these mediators, if recalled, as cues for retrieving the correct response. Dunlosky and Hertzog's findings are consistent with our interpretation of the present results in terms of an aging-induced deficit in the associative component of episodic memory (cf. Li, NavehBenjamin, \& Lindenberger, 2005). The precise nature of this associative deficit requires further study. For instance, we know little of its relative magnitude and temporal dynamics in the course of encoding, consolidation, and retrieval.

\section{Limitations of the Present Study}

In interpreting the results of the present study, a number of limitations need to be kept in mind. First, in order to minimize differences in selectivity between age groups, we positively selected the present study sample. Hence, the amount of memory plasticity obtained in this study is likely to be an overestimate of the average level of memory plasticity in the population. The ceiling effect of younger adults in the postinstruction session is another limitation, as it prevented the separation of practice gains from instruction gains in younger adults. Future studies on episodic memory plasticity need to refine experimental procedures to better capture age differences during all stages of learning.

For practical reasons, our life-span comparison of episodic memory plasticity was limited to only four discrete age groups (younger children, older children, younger adults, and older adults). This selection inevitably missed some other important age groups, such as children below the age of 9 years, middle-aged adults, and very old individuals. Future studies should consider a further extension of age ranges, especially at the two extremes of the life span.

Finally, the key dependent variable in the present study was the timed recall score, which expressed the relation between encoding time and the number of correctly recalled items. One assumption underlying this score is that participants in all age groups attempt to make effective use of limited encoding time to form taskrelevant associations quickly. Previous age-comparative memory research in the field of cognitive aging supports this assumption (Kliegl \& Lindenberger, 1993; Kliegl et al., 1994). In addition, life-span comparisons in the domains of working memory and inductive reasoning have successfully used similar procedures (Mayr, Kliegl, \& Krampe, 1996). Nevertheless, further methodological work examining the functional age equivalence of the timed recall score is desirable. On a more technical level, it is worth noting that the present pattern of results remained unaltered when encoding times were kept in their raw score metric instead of being log transformed.

\section{Conclusion and Outlook}

This study provides initial evidence for substantial life-span differences in memory plasticity from middle childhood to early old age. As a conceptual framework for the study of latent potential across the life span, the distinctions between baseline performance, baseline plasticity, and developmental plasticity (e.g., Baltes, 1987) proved to be useful for capturing the predicted magnification of life-span age differences in episodic memory performance after instruction and training. Children showed similar amounts of baseline plasticity in episodic memory performance as did older adults but substantially greater amounts of developmental plasticity than did older adults. Future research needs to move toward process-oriented accounts of life-span differences in memory plasticity by examining the contributions of maturation, senescence, and experiential factors as well as their intricate interactions at both neuronal and behavioral levels of analysis. We also noted commonalities between the present conceptual framework and research in child development on the contributions of strategy acquisition, spontaneous strategy use, and strategy effectiveness that merit further exploration. As a first approximation, the distinction between strategic and associative components of episodic memory may play a fruitful role in this endeavor. Furthermore, our results also show a great amount of interindividual differences in encoding times (Figure 1) and learning curves (Figure 3), particularly at either end of the life span. The presence of substantial variability within and between individuals supports the long-standing claim of adopting a within-person methodology to the study of behavioral change (e.g., Lindenberger \& von Oertzen, 2006; Nesselroade, 1991). Multilevel latent growth curve models that jointly analyze within-person changes and between-person differences are a first step in this direction (e.g., Lövdén, Brehmer, Li, \& Lindenberger, 2006).

\section{References}

Baltes, P. B. (1987). Theoretical propositions of life-span developmental psychology: On the dynamics between growth and decline. Developmental Psychology, 23, 611-626.

Baltes, P. B., \& Kliegl, R. (1992). Further testing of limits of cognitive plasticity: Negative age differences in a mnemonic skill are robust. Developmental Psychology, 28, 121-125.

Baltes, P. B., \& Lindenberger, U. (1988). On the range of cognitive plasticity in old age as a function of experience: 15 years of intervention research. Behavior Therapy, 19, 283-300. 
Baltes, P. B., Lindenberger, U., \& Staudinger, U. M. (2006). Life span theory in developmental psychology. In R. M. Lerner (Ed.), Handbook of child psychology: Theoretical models of human development (6th ed., Vol. 1, pp. 569-664). New York: Wiley.

Bjorklund, D. F., Miller, P. H., Coyle, T. R., \& Slawinski, J. L. (1997). Instructing children to use memory strategies: Evidence of utilization deficiencies in memory training studies. Developmental Review, 17, 411-441.

Bower, G. H. (1970). Analysis of a mnemonic device. American Scientist, 58, 496-510.

Brainerd, C. J. (1974). Training and transfer of transitivity, conservation, and class inclusion of length. Child Development, 45, 324-334.

Brehmer, Y., Müller, V., Oertzen, T. v., \& Lindenberger, U. (2004). Episodic memory in childhood and old age: The role of cortical coherence. In A. Mecklinger, H. Zimmer, \& U. Lindenberger (Eds.), Bound in memory: Insights from behavioral and neuropsychological studies (pp. 69-91). Herzogenrath: Shaker.

Brehmer, Y., Stoll, G., Bergner, S., Benoit, R., Oertzen, T. v., \& Lindenberger, U. (2004). Selection of high-imagery words for age-comparative memory experiments. Saarbrücken: Saarland University Technical Report, 2005. Retrieved June 14, 2004, from http://psydok.sulb.unisaarland.de/volltexte/2004/189/

Brown, G. D. A., Vousden, J. I., McCormack, T., \& Hulme, C. (1999). The development of memory for serial order: A temporal-contextual distinctiveness model. International Journal of Psychology, 34, 389-402.

Cherry, K. E., Park, D. C., Frieske, D. A., \& Rowley, R. L. (1993). The effect of verbal elaborations on memory in young and older adults. Memory and Cognition, 21, 725-738.

Cowan, N. (1997). The development of working memory. In N. Cowan (Ed.), The development of memory in childhood (pp. 163-199). Hove, England: Psychology Press.

Craik, F. I. M. (2006). Remembering items and their contexts: Effects of aging and divided attention. In H. Zimmer, A. Mecklinger, \& U. Lindenberger (Eds.), Binding in human memory: A neurocognitive perspective (pp. 571-594). Oxford, England: Oxford University Press

Craik, F. I. M., \& Bialystok, E. (2006). On structure and process in lifespan cognitive development. In E. Bialystok \& F. I. M. Craik (Eds.), Lifespan cognition: Mechanisms of change (pp. 3-13). Oxford, England: Oxford University Press.

Denney, N. W. (1984). A model of cognitive development across the life span. Developmental Review, 4, 171-191.

Dunlosky, J., \& Hertzog, C. (1998). Aging and deficits in associative memory: What is the role of strategy production? Psychology and Aging, 13, 597-607.

Dunlosky, J., Hertzog, C., \& Powell-Moman, A. (2005). The contribution of mediator-based deficiencies to age differences in associative learning. Developmental Psychology, 41, 389-400.

Ericsson, K. A., Krampe, R. T., \& Tesch-Römer, C. (1993). The role of deliberate practice in the acquisition of expert performance. Psychological Review, 100, 363-406.

Flavell, J. H. (1992). Cognitive development: Past, present, and future. Developmental Psychology, 28, 998-1005.

Hill, R. D., Bäckman, L., \& Stigsdotter Neely, A. (2000). Cognitive rehabilitation in old age. New York: Oxford University Press.

Hulicka, I. M., \& Grossman, J. L. (1967). Age group comparisons for the use of mediators in paired-associate learning. Journal of Gerontology, 22, 46-51.

Kausler, D. H. (1994). Learning and memory in normal aging. New York: Academic Press.

Kliegl, R., \& Baltes, P. B. (1987). Theory-guided analysis of mechanisms of development and aging mechanisms through testing-the-limits and research on expertise. In C. Schooler \& K. W. Schaie (Eds.), Cognitive functioning and social structure over the life course (pp. 95-119). Norwood, NJ: Ablex.
Kliegl, R., \& Lindenberger, U. (1993). Modeling intrusions and correct recall in episodic memory: Adult age differences in encoding of list context. Journal of Experimental Psychology: Learning, Memory, and Cognition, 19, 617-637.

Kliegl, R., Mayr, U., \& Krampe, R. T. (1994). Time-accuracy functions for determining process and person differences: An application to cognitive aging. Cognitive Psychology, 26, 134-164.

Kliegl, R., Smith, J., \& Baltes, P. B. (1989). Testing-the-limits and the study of adult age differences in cognitive plasticity of a mnemonic skill. Developmental Psychology, 25, 247-256.

Kramer, A. F., \& Willis, S. L. (2003). Cognitive plasticity and aging. Psychology of Learning and Motivation, 43, 267-302.

Kuhn, D. (1995). Microgenetic study of change: What has it told us? Psychological Science, 6, 133-139.

Li, S-C. (2003). Biocultural orchestration of developmental plasticity across levels: The interplay of biology and culture in shaping the mind and behavior across the life span. Psychological Bulletin, 129, 171-194.

Li, S-C., Brehmer, Y., Shing, Y. L., Werkle-Bergner, M., \& Lindenberger, U. (2006). Neuromodulation of associative and organizational plasticity across the life span: Empirical evidence and neurocomputational modeling. Neuroscience and Biobehavioral Reviews, 30, 775-790.

Li, S-C., Lindenberger, U., Hommel, B., Aschersleben, G., Prinz, W., \& Baltes, P. B. (2004). Transformation in the coupling among intellectual abilities and constituent cognitive processes across the life span. Psychological Science, 15, 155-163.

Li, S-C., Naveh-Benjamin, M., \& Lindenberger, U. (2005). Aging neuromodulation impairs associative binding: A neurocomputational account. Psychological Science, 16, 445-450.

Lindenberger, U. (2000). Intellektuelle Entwicklung über die Lebensspanne: Überblick und ausgewählte Forschungsbrennpunkte. [Intellectual development across the life span: Overview and research perspectives.] Psychologische Rundschau, 51, 135-145.

Lindenberger, U., \& Baltes, P. B. (1995). Testing-the-limits and experimental simulation: Two methods to explicate the role of learning in development. Journal of Human Development, 38, 349-360.

Lindenberger, U., \& Baltes, P. B. (1997). Intellectual functioning in old and very old age: Cross-sectional results from the Berlin Aging Study. Psychology and Aging, 12, 410-432.

Lindenberger, U., Kliegl, R., \& Baltes, P. B. (1992). Professional expertise does not eliminate negative age differences in imagery-based memory performance during adulthood. Psychology and Aging, 7, 585-593.

Lindenberger, U., Mayr, U., \& Kliegl, R. (1993). Speed and intelligence in old age. Psychology and Aging, 8, 207-220.

Lindenberger, U., Singer, T., \& Baltes, P. B. (2002). Longitudinal selectivity in aging populations: Separating mortality-associated versus experimental components in the Berlin Aging Study (BASE). Journal of Gerontology: Psychological Science, 57B, 474-482.

Lindenberger, U., \& von Oertzen, T. (2006). Variability in cognitive aging: From taxonomy to theory. In E. Bialystok \& F. I. M. Craik (Eds.), Lifespan cognition (pp. 297-314). Oxford, England: Oxford University Press.

Lövdén, M., Brehmer, Y., Li, S.-C., \& Lindenberger, U. (2006). Plasticity of episodic memory performance in middle childhood to old age: Revisiting the magnification model. Manuscript in preparation.

Mayr, U., Kliegl, R., \& Krampe, R. T. (1996). Sequential and coordinative processing dynamics in figural transformations across the life span. Cognition, 59, 61-90.

McArdle, J. J., Ferrer-Caja, E., Hamagami, F., \& Woodcock, R. W. (2002). Comparative longitudinal structural analyses of the growth and decline of multiple intellectual abilities over the life span. Developmental Psychology, 38, 115-142.

Miller, E. K., \& Cohen, J. D. (2001). An integrative theory of prefrontal cortex function. Annual Review of Neuroscience, 24, 167-202.

Miller, P. H. (1990). The development of strategies of selective attention. 
In D. F. Bjorklund (Ed.), Children's strategies: Contemporary views of cognitive development (pp. 157-184). Hillsdale, NJ: Erlbaum.

Naveh-Benjamin, M. (2000). Adult age differences in memory performance: Tests of an associative deficit hypothesis. Journal of Experimental Psychology: Learning, Memory, and Cognition, 26, 1170-1187.

Nelson, C. A. (2002). The ontogeny of human memory: A cognitive neuroscience perspective. In M. Johnson, Y. Munakata, \& R. O. Gilmore (Eds.), Brain development and cognition: A reader (pp. 151-178). Oxford, England: Blackwell

Nesselroade, J. R. (1991). Inter-individual differences in intra-individual change. In L. M. Collins \& J. L. Horn (Eds.), Best methods for the analysis of change (pp. 92-105). Washington, DC: American Psychological Association.

Nyberg, L. (2005). Cognitive training in healthy aging. In R. Cabeza, L. Nyberg, \& D. C. Park (Eds.), Cognitive neuroscience of aging (pp. 309-321). Oxford, England: Oxford University Press.

Ornstein, P. A., \& Haden, C. A. (2001). Memory development or the development of memory? Current Directions in Psychological Science, $10,202-205$

Piaget, J. (1952). The origins of intelligence in children. New York: Norton.

Pressley, M., \& Levin, J. R. (Eds.). (1983). Cognitive strategy research: Educational applications. New York: Springer.

Prull, M. W., Gabrieli, J. D. E., \& Bunge, S. A. (2000). Age-related changes in memory: A cognitive neuroscience perspective. In F. I. M. Craik \& T. A. Salthouse (Eds.), The handbook of aging and cognition (2nd ed., pp. 91-153). Mahwah, NJ: Erlbaum.

Reese, H. W. (1962). Verbal mediation as a function of age level. Psychological Bulletin, 59, 502-509.

Roediger, H. L. (1980). The effectiveness of four mnemonics in ordering recall. Journal of Experimental Psychology: Human Learning and Memory, 6, 558-567.

Rohwer, W. D., Jr. (1973). Elaboration and learning in childhood and adolescence. In H. W. Reese (Ed.), Advances in child development and behavior (Vol. 8, pp. 2-57). New York: Academic Press.

Schlagmüller, M., \& Schneider, W. (2002). The development of organizational strategies in children: Evidence from a micro-genetic longitudinal study. Journal of Experimental Child Psychology, 81, 298-319.
Siegler, R. S. (2004). Turning memory development inside out. Developmental Review, 24, 469-475.

Siegler, R. S., \& Crowley, K. (1991). The microgenetic method. A direct means for studying cognitive development. American Psychologist, 46, $606-620$.

Singer, T., Lindenberger, U., \& Baltes, P. B. (2003). Plasticity of memory for new learning in very old age: A story of major loss? Psychology and Aging, 18, 306-317.

Sowell, E. R., Thompson, P. M., Tessner, K. D., \& Toga, A. W. (2001) Accelerated brain growth and cortical gray matter thinning are inversely related during post adolescent frontal lobe maturation. NeuroImage, 13, 1103.

Stevenson, H. (1983). How children learn: The quest for a theory. In W. Kessen (Ed.) \& P. H. Mussen (Series Ed.), Handbook of child psychology: Vol. 1. History, theory, and methods (pp. 213-236). New York: Wiley.

Stuss, D. T., \& Alexander, M. P. (2005). Does damage to the frontal lobes produce impairment in memory? Current Directions in Psychological Science, 14, 84-88.

Treat, N. J., \& Reese, H. W. (1976). Age, imagery, and pacing in pairedassociate learning. Developmental Psychology, 12, 119-124.

Verhaeghen, P., Marcoen, A., \& Goossens, L. (1992). Improving memory performance in the aged through mnemonic training: A meta-analytic study. Psychology and Aging, 7, 242-251.

Vygotsky, L. S. (1978). Mind in society. Cambridge, MA: Harvard University Press.

Wechsler, D. (1958). The measurement and appraisal of adult intelligence (4th ed.). Baltimore, MD: Williams \& Wilkins.

Werkle-Bergner, M., Müller, V., Li, S-C., \& Lindenberger, U. (2006) Cortical EEG correlates of successful memory encoding: Implications for lifespan comparisons. Neuroscience \& Biobehavioral Reviews, 30, 839-854.

Yesavage, J. A., \& Rose, T. L. (1984). Semantic elaboration and the method of loci: A new trip for older learners. Experimental Aging Research, 10, 155-159.

Received August 22, 2005

Revision received October 27, 2006

Accepted November 6, 2006

\section{E-Mail Notification of Your Latest Issue Online!}

Would you like to know when the next issue of your favorite APA journal will be available online? This service is now available to you. Sign up at http://watson.apa.org/ notify/ and you will be notified by e-mail when issues of interest to you become available! 